\title{
QUANDO O PACIENTE SUBMETIDO A CIRURGIA BARIÁTRICA RECEBE ALTA?
}

\author{
When bariatric patients are free of assisted fallow-up?
}

Isac Jorge FILHO*

ABCDDV/629

Jorge-Filho I. Quando o paciente submetido a cirurgia bariátrica recebe alta? ABCD Arq Bras Cir Dig 2009;22(1):1

Os hábitos alimentares impostos pelo "modo de vida norte-americano" transformaram a obesidade em problema de saúde pública. Mesmo em países onde ainda existe parcela da população com problema nutricional inverso, a adoção desses hábitos alimentares tem feito crescer consideravelmente o número de obesos. $\mathrm{O}$ advento dos recursos cirúrgicos para o tratamento da obesidade mórbida encontrou ambiente populacional propício e, conseqüentemente, o número de pacientes submetidos a esse tipo de tratamento tem aumentado amplamente em todo o mundo ocidental. Hoje não se discute mais a respeito dos benefícios que uma operação bem indicada e bem conduzida acarreta para o portador de obesidade acompanhada de problemas mórbidos associados. Em congressos e periódicos se discute muito em torno de variantes técnicas e resultados. No entanto, pouco se tem falado a respeito de como o paciente vai passar ao longo de sua vida póscirurgia. Como deve ser o controle pós-operatório? Por quanto tempo? Quando terá alta? Qual é o custo para o organismo das alterações anátomo-fisiológicas determinadas pela operação?

Aqui não se pode deixar de traçar um paralelo com as operações de ressecção gastro-duodenal realizadas por muitos e muitos anos para tratamento da úlcera péptica. Mesmo se considerando extremos cuidados na indicação e condução do procedimento operatório não se podia fugir do fato básico: para se tratar a úlcera procedia-se uma agressão cirúrgica que implicava modificações anátomo-fisiológicas que muitas vezes cobravam seu preço, na forma das temíveis síndromes pós-gastrectomia. Na cirurgia bariátrica a preocupação deve ser maior, já que altera mecanismos mais sensíveis, como os da digestão e absorção dos diferentes nutrientes. Assim, é importante que fique claro para o cirurgião e equipe que, ao operar, ele vai passar a ter um paciente com grande potencial de complicações pós-operatórias. E tais complicações tem

Endereço para correspondência: Isac Jorge Filho, e-mail: ijfilho@gmail.com aparecido, com frequência considerável. São hematológicas, eletrolíticas e neurológicas, entre outras, e podem aparecer precoce ou tardiamente. Koffman et al. ${ }^{3}$ publicaram, em 2006, uma revisão de literatura analisando 96 pacientes com sintomas neurológicos após cirurgia bariátrica. A neuropatia periférica representou $62 \%$ dos casos e a encefalopatía $31 \%$. Emergências neurológicas como a encefalopatia de Wernicke, a rabdomiólise e a síndrome de Guillain-Barré foram também encontradas. Em 18 séries cirúrgicas reportadas entre 1976 e 2004, 133 de 9996 pacientes $(1,3 \%)$ tiveram complicações neurológicas. Para diagnosticar e tratar esses pacientes em tempo e corretamente eles devem ser entendidos como pacientes que nunca terão alta, respondendo a pergunta que dá título a este editorial. Em trabalho recente Billet et al. ${ }^{1}$, referindo-se aos exames hematológicos e dosagem do ferro sérico, recomendam: "Os pacientes submetidos a cirurgia bariátrica requerem seguimento ao longo da vida, já que podem manifestar carência muitos anos após a cirurgia". Infelizmente não é sempre assim que tem sido feito. Brolin e Leung ${ }^{2}$ enviaram questionários para 109 cirurgiões querendo saber como se comportavam quanto ao uso rotineiro de suplementos e de exames solicitados no pós-operatório. As respostas mostraram grande variação de condutas. Quanto ao intervalo entre os exames chegou a $4 \%$ o porcentual de cirurgiões que não pedia exames de rotina, o que justifica plenamente a preocupação externada neste editorial.

*Conselheiro do Conselho Regional de Medicina do Estado de São Paulo - CREMESP e Titular especialista do colégio Brasileiro de Cirurgia Digestiva - CBCD

\section{REFERÊNCIAS}

1. Billet SE, Kortuem KR, Gibson LE, El-Azhary R. A morbilliform variant of vancomycin-induced linear IgA bullous dermatosis. Arch Dermatol. 2008 Jun;144(6):774-8.

2. Brolin RE, Leung M. Survey of vitamin and mineral supplementation after gastric bypass and biliopancreatic diversion for morbid obesity. Obes Surg. 1999 Apr;9(2):150-4.

3. Koffman BM, Greenfield LJ, Ali II, Pirzada NA. Neurologic complications after surgery for obesity. Muscle Nerve. 2006 Feb;33(2):166-76.

Fonte de financiamento: não há Conflito de interesse: não há Recebido para publicação: 25/07/2008 Aceito para publicação: 28/09/2008 